\title{
A case study of a sporadic sodium layer observed by the ALOMAR Weber Na lidar
}

\author{
H. Nesse ${ }^{1,2}$, D. Heinrich ${ }^{1}$, B. Williams ${ }^{3}$, U.-P. Hoppe ${ }^{1}$, J. Stadsnes ${ }^{2}$, M. Rietveld ${ }^{4}$, W. Singer ${ }^{5}$, U. Blum ${ }^{1,6}$, \\ M. I. Sandanger ${ }^{2}$, and E. Trondsen ${ }^{7}$ \\ ${ }^{1}$ Norwegian Defence Research Establishment, Kjeller, Norway \\ ${ }^{2}$ University of Bergen, Department of Physics and Technology, Bergen, Norway \\ ${ }^{3}$ NorthWest Research Associates/Colorado Research Associates Division, Boulder, USA \\ ${ }^{4}$ EISCAT Scientific Association, Troms $\varnothing$, Norway \\ ${ }^{5}$ Leibniz Institute for Atmospheric Physics, Kühlungsborn, Germany \\ ${ }^{6}$ Fraunhofer Institute for Technological Trend Analysis, Euskirchen, Germany \\ ${ }^{7}$ University of Oslo, Department of Physics, Oslo, Norway
}

Received: 15 December 2006 - Revised: 23 March 2007 - Accepted: 30 March 2007 - Published: 28 May 2008

\begin{abstract}
Several possible mechanisms for the production of sporadic sodium layers have been discussed in the literature, but none of them seem to explain all the accumulated observations. The hypotheses range from direct meteoric input, to energetic electron bombardment on meteoric smoke particles, to ion neutralization, to temperature dependent chemistry. The varied instrumentation located on Andøya and near Troms $\varnothing$ in Norway gives us an opportunity to test the different theories applied to high latitude sporadic sodium layers. We use the ALOMAR Weber sodium lidar to monitor the appearance and characteristics of a sporadic sodium layer that was observed on 5 November 2005. We also monitor the temperature to test the hypotheses regarding a temperature dependent mechanism. The EISCAT Troms $\varnothing$ Dynasonde, the ALOMAR/UiO All-sky camera and the SKiYMET meteor radar on Andøya are used to test the suggested relationships of sporadic sodium layers and sporadic E-layers, electron precipitation, and meteor deposition during this event. We find that more than one candidate is eligible to explain our observation of the sporadic sodium layer.
\end{abstract}

Keywords. Atmospheric composition and structure (Ion chemistry of the atmosphere; Thermosphere-composition and chemistry) - Ionosphere (Ionosphere-atmosphere interactions; Ionospheric irregularities)

\section{Introduction}

A sporadic sodium layer, also called a sudden sodium layer, is a narrow layer in which a sudden increase of sodium ( $\mathrm{Na}$ )

Correspondence to: $\mathrm{H}$. Nesse

(hne@ffi.no) is observed. Such layers mainly occur at altitudes between 90 and $110 \mathrm{~km}$ (von Zahn and Hansen, 1988; Hansen and von Zahn, 1990). Sporadic Na layers have concentrations between 2 and 20 times that of the background layer, and a typical width of less than $2 \mathrm{~km}$ (Clemesha, 1995). They are often observed to appear in a matter of minutes, but can persist for as long as a few hours, and then disappear rapidly (Gardner et al., 1995) or slowly fade into the background (Heinrich et al., 2008). Since the first report of a sporadic Na layer in 1978 (Clemesha et al., 1978), several possible production mechanisms have been proposed, but none of them seem to explain all the accumulated measurements. A satisfactory theory must explain the formation of extremely thin layers with horizontal dimensions varying from about one hundred to thousands of kilometers (Batista et al., 1991). It must account for the fact that the sporadic Na layers are not seen below $90 \mathrm{~km}$, and for an apparent correlation with sporadic $\mathrm{E}$ layers. Unless we believe in the existence of multiple mechanisms, it also has to work globally to explain how this phenomenon occurs at a broad range of latitudes (Clemesha, 1995).

We will limit our investigation and discussion of sporadic $\mathrm{Na}$ layers to auroral latitudes. We will use sodium density measurements from the ALOMAR Weber Na lidar located at Andøya in Norway (She et al., 2002) to monitor the appearance and characteristics of a sporadic Na layer. Measurements at auroral latitudes have previously been made at sites such as Andøya (von Zahn and Hansen, 1988; Williams et al., 2006), Poker Flat, Alaska (Collins et al., 1996) and Sondrestrom, Greenland (Heinselman et al.,1998).

Most case studies trying to identify the production mechanism of sporadic Na layers seem to focus on only one of the proposed theories (e.g. Gu et al., 1995). The varied

Published by Copernicus Publications on behalf of the European Geosciences Union. 
instrumentation at and near Andøya gives us, however, an opportunity to test several different theories applied to highlatitude sporadic Na layers. We will revisit three theories that have been dismissed by earlier work, such as the theories concerning direct meteoric input (Clemesha et al., 1978, 1988), precipitating auroral particles acting on meteoric smoke particles (von Zahn et al., 1987) and temperature dependent chemistry (Zhou et al., 1993; Zhou and Mathews, 1995). The more accepted ion neutralization theory in sporadic E-layers (Cox and Plane, 1998) will also be addressed. We should stress that a single case study will not constitute a definitive result, but a simultaneous evaluation of the different theories is important when considering whether or not there is more than one mechanism at work.

In Sect. 2 we will briefly present the instrumentation and the measurement products that are used. Section 3 addresses the characteristics of a sporadic Na layer seen on 5 November 2005. In Sect. 4 we investigate the suggested connections of the sporadic Na layer and sporadic E layers, electron precipitation, temperature variations, and meteor deposition to see which of the proposed formation mechanisms is best fit to explain our observation. Final comments and conclusions are given in Sect. 5.

\section{The instrumentation}

The complementary instrumentation at Andøya and near Troms $\varnothing$ in Norway gives us an opportunity to test several of the proposed mechanisms for sporadic Na layers. Using the Na density measurements from the ALOMAR Weber Na lidar, we can monitor the appearance and characteristics of sporadic Na layers. We will use the EISCAT Troms $\varnothing$ Dynasonde, the ALOMAR/UiO all-sky camera and the SKiYMET meteor radar on Andøya to test the suggested connections of sporadic sodium layers and sporadic E-layers, electron precipitation, and meteor deposition.

\subsection{The ALOMAR Weber Na lidar}

The ALOMAR Weber Na lidar is a Na fluorescence lidar (She et al., 2002; Vance et al., 1998; Arnold and She, 2003). This instrument is used to determine the Na density profiles, as well as atmospheric temperature and wind from about 80 to $100 \mathrm{~km}$ by remote spectroscopy. The instrument is part of the Arctic Lidar Observatory for Middle Atmosphere Research (ALOMAR), located at Andøya in Norway $\left(69.2^{\circ} \mathrm{N}\right.$, $\left.16.0^{\circ} \mathrm{E}\right)$.

The lidar system emits light at three known frequencies in a sequential order. A small fraction of the emitted light is resonantly scattered by atmospheric $\mathrm{Na}$ atoms, which exist in the mesopause region due to meteor ablation. The measured intensities are fitted to the theoretical shape of the spectrum of the $\mathrm{D}_{2}$ transition of the $\mathrm{Na}$ atom, which depends on the atmospheric temperature and the line-of-sight wind (Heinrich et al., 2005). Assuming that vertical wind is zero we can calculate the zonal or meridional wind component as the beam is tilted off zenith. The Na number density is calculated using the following equation (Fricke and von Zahn, 1985):

$n_{\mathrm{Na}}\left(z_{\mathrm{Na}}\right)=n_{s t}\left(z_{s t}\right) \cdot \frac{\sigma\left(180^{\circ}\right)_{s t}}{\sigma\left(180^{\circ}\right)_{\mathrm{Na}}}\left[\frac{z_{\mathrm{Na}}}{z_{S t}}\right]^{2} \cdot \frac{I_{\mathrm{Na}}}{I_{s t}}$

where $I_{\mathrm{Na}} / I_{s t}$ is the ratio of the observed count rates in the $\mathrm{Na}$ layer and the Rayleigh reflected signal from the stratosphere at each of the frequencies to which the lidar is tuned. The square of the ratio of the altitudes $z$ compensates for the variation of solid angles subtended by the receiving mirror at the respective scattering volumes. $\sigma\left(180^{\circ}\right)$ are the backscattering cross sections for resonance scattering $(\mathrm{Na})$ and Rayleight scattering (st). The atmospheric gas density in the stratosphere is denoted by $n_{s t}\left(z_{s t}\right)$.

\subsection{The SKiYMET meteor radar}

The ablation of meteoroids entering the upper atmosphere is probably the most important source for the Na layer. The meteor radar located at Andøya observes the incoming meteoroids $24 \mathrm{~h}$ each day throughout the year under all weather conditions. The transmitting antenna radiates electromagnetic pulses at $32.5 \mathrm{MHz}$. The detection antenna system applies crossed antenna elements to ensure sensitivity nearly uniform in azimuth and for elevation angles greater than $20^{\circ}$. A three-element Yagi antenna is used on transmission. On reception a five-antenna interferometer provides a resolution of $2^{\circ}$ in meteor location with a range resolution of $2 \mathrm{~km}$ corresponding to a 13-microsecond pulse width. From each meteor the radial velocity of the meteor trail due to its movement with the background wind is estimated (for details see Hocking and Thayaparan, 1997). We will compare the height distribution and the number of observed meteor echoes before and during the period of the observed sporadic Na layer.

\subsection{The EISCAT Troms $\varnothing$ Dynasonde}

The EISCAT Troms $\varnothing$ Dynasonde is located on Ramfjordmoen $\left(69.2^{\circ} \mathrm{N}, 19.6^{\circ} \mathrm{E}\right)$. This is approximately $128 \mathrm{~km}$ north east of ALOMAR. The dynasonde is a digital HF sounder covering approximately $1-30 \mathrm{MHz}$. Two identical receivers are tuned to the frequency that is being transmitted, and six dipole receiving antennas are deployed in an array. By combining measurements obtained from the receiving-antenna array, we can derive the parameters of echo amplitude, signal-to-noise ratio, echo location, and Doppler ionogram records (Pitteway and Wright, 1992).

We will mainly use ionograms to explore the existence of possible sporadic E-layers. A wide variety of phenomena are included under the name of sporadic E-layer. The sporadic E-layer echoes found in an ionogram are usually divided into nine standard types. When looking for a correlation between sporadic Na layers and sporadic E-layer we are interested 

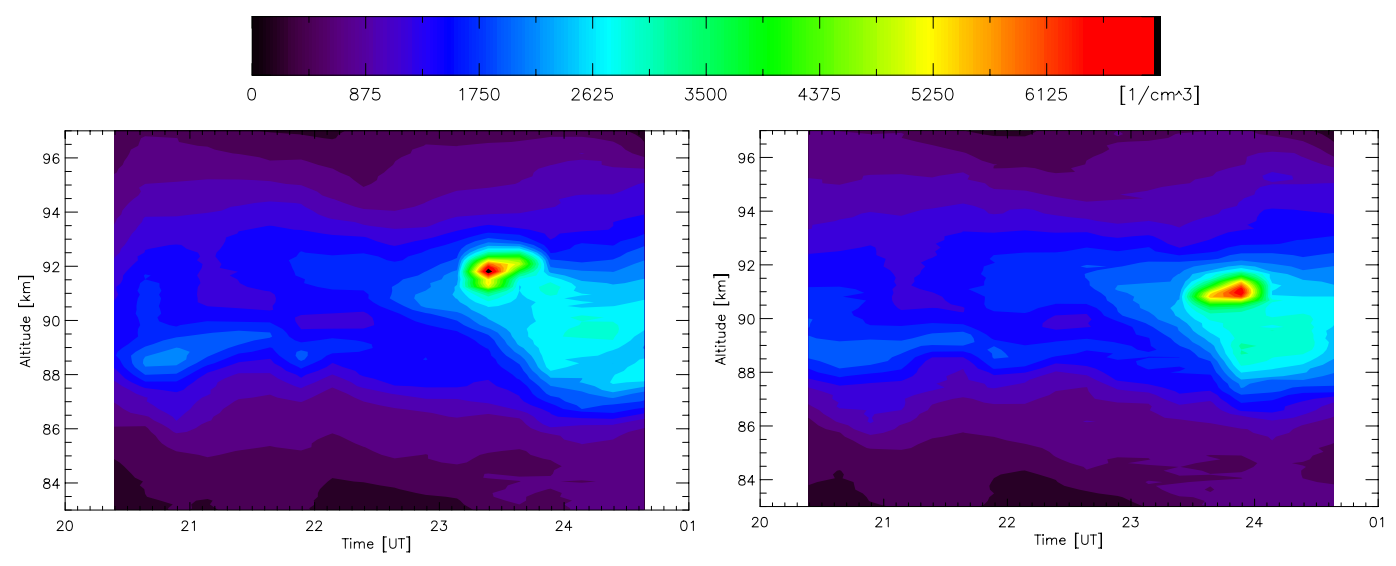

Fig. 1. Contour plots of $15 \mathrm{~min}$ averaged density from the ALOMAR Weber Na lidar on 5-6 November 2005. Beam 1 (left) is pointing $20^{\circ} \mathrm{W}$ of zenith. Beam 2 (right) is pointing $20^{\circ} \mathrm{E}$ of zenith.

in echoes fitting the description of a low sporadic E-layer, which is a flat trace at or below the normal E-layer minimum virtual height.

\subsection{The ALOMAR/UiO all-sky camera}

The All-sky Imager at Andøya owned by the University of Oslo (UiO) and ALOMAR, is operated using two wavelength filters, $557.7 \mathrm{~nm}$ and $630.0 \mathrm{~nm}$, respectively. Both of these wavelengths correspond to energy level transitions in oxygen atoms, with statistical lifetimes of $0.7 \mathrm{~s}$ and $120 \mathrm{~s}$. The dominant quenching partners are molecular oxygen and nitrogen. Qualitatively, this means that measured intensities in the $630.0 \mathrm{~nm}$ band correspond to the soft part of the energy spectra, while the observed intensities in $557.7 \mathrm{~nm}$ are related to the more energetic particles. We will use observations of the all-sky camera to look for correlation between particle precipitation and sporadic Na layers. The intensity ratio of the two wavelength bands can in theory also be used to estimate the characteristic energy of the precipitation, but since they both have rather long lifetimes it is not ideal (Rees and Luckey, 1974). The ratio will reveal little information about the energy needed to penetrate down to $90 \mathrm{~km}$. Since the ALOMAR/UiO All-sky Imager is not calibrated, we will use the intensity ratio only as an indication of the relative variation of the characteristic energy of the electron precipitation.

\section{Observation and characterisation of a sporadic $\mathrm{Na}$ layer}

On 5 November 2005 we started measuring with the ALOMAR Weber Na lidar around 15:10 UT and continued till 6 November 00:45 UT. We will focus on the last hours where we detected a sudden increase in the Na density at about 91$92 \mathrm{~km}$ as seen in Fig. 1. The density increase is first apparent in beam 1, pointed $20^{\circ} \mathrm{W}$ of zenith, just after 23:00 UT for about $30 \mathrm{~min}$. It is observed in beam 2, directed $20^{\circ} \mathrm{E}$ of zenith, at about 23:30 UT, also for about $30 \mathrm{~min}$. The time delay between the appearances in the two beams is in reasonable agreement with the measured neutral zonal wind transporting the density increase from the field of view in beam 1 to beam 2. In this section we will investigate the properties of the observed sporadic $\mathrm{Na}$ layer.

Sporadic Na layers typically have concentrations between 2 and 20 times that of the background layer. On 5 November 2005, we find a density increase of a factor $\sim 3-4$ within $15 \mathrm{~min}$ as seen in Fig. 2. Whether this growth is the actual formation time or a result of advection needs some consideration. The sudden Na density increase is observed in beam 1 for about $30 \mathrm{~min}$ before it appears in beam 2, in agreement with the average neutral zonal wind measured in the two beams at the specific height and time. This means that the growth observed in beam 2 is most likely due to advection, and does not represent the production time. We find about the same growth rate in both beams, which might indicate that the observed increase in beam 1 is also due to advection. The duration of this sporadic Na layer is shorter than generally observed by the Weber lidar. Often the layers over ALOMAR last many hours during which the layer moves up or down in height while the width generally increases (Williams et al., 2004, 2006).

Batista et al. (1991) found the sporadic Na layers to exist in patches with horizontal dimensions between 100 and $2000 \mathrm{~km}$. Our two beams are separated by about $65 \mathrm{~km}$ at $90 \mathrm{~km}$ altitude. We have some overlap between the observations of the sporadic Na-layer in the two beams, which indicates a horizontal dimension of more than $65 \mathrm{~km}$. If we consider the measured zonal wind and the duration of the observation in the beams separately, we get a somewhat ambiguous result concerning the zonal extent. The observation in beam 1 suggests a zonal dimension of approximately $40 \mathrm{~km}$, 

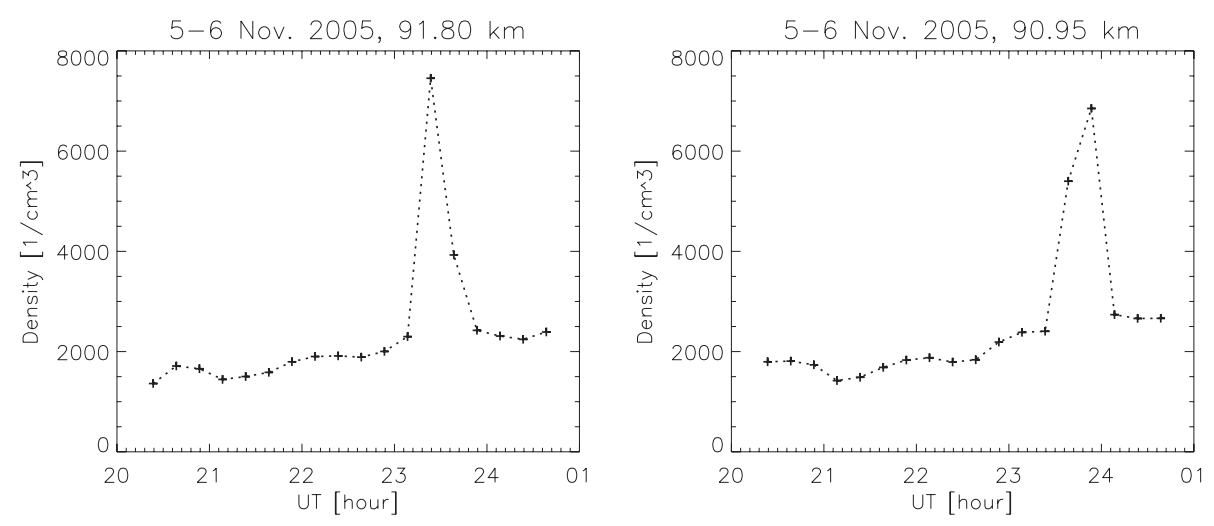

Fig. 2. 15 min averaged densities from the ALOMAR Weber Na lidar on 5-6 November 2005 at the height of maximum density increase. Beam 1 (left) is pointing $20^{\circ} \mathrm{W}$ of zenith. Beam 2 (right) is pointing $20^{\circ} \mathrm{E}$ of zenith.

while the observations in beam 2 suggest a zonal extent of about $100 \mathrm{~km}$. This ambiguity might suggest the existence of a meridional wind, or that the observed $\mathrm{Na}$ layer is growing in horizontal size, or that the edge of the layer is not $90^{\circ}$ with the prevailing wind. All three possibilities are probable, as well as any combination.

The maximum intensity of the sudden $\mathrm{Na}$ density increase is found at $91.80 \mathrm{~km}$ in beam 1 and at $90.95 \mathrm{~km}$ in beam 2 . This seems to be at the lower edge of the winter observations of sporadic Na layers at Andøya reported by Hansen and von Zahn (1990). The vertical thickness is about $2 \mathrm{~km}$ (full width half maximum). Hansen and von Zahn (1990) found a local time dependence in the observations of the sporadic Na layer at Andøya. They observed 75 sporadic Na layers, which all occurred between 20:00 and 02:00 LT, with maximum occurrence at 22:00 LT. Heinrich et al. (2008) also found a similar local time dependence using the ALOMAR Weber Na lidar. From 2000 to 2006 they observed 31 sporadic Na layers, which all with the exception of one, occurred in this time interval. We observe the sudden $\mathrm{Na}$ density increase between 00:20-01:00 LT. Because of the characteristics summarised above, we consider our observation a sporadic $\mathrm{Na}$ layer.

\section{Possible formation mechanisms}

Several possible mechanisms for the production of sporadic $\mathrm{Na}$ layers have been discussed in the literature, but none of them seem to provide an altogether satisfactory explanation. A mechanism must explain the formation and disappearance of extremely dense and thin layers, their altitude distribution, and their vertical and horizontal extents. Unless we believe there is more than one mechanism involved, it must act at all latitudes. In this section we will investigate four possible formation mechanisms to see which of them best explains our observations.

\subsection{Connection to meteor deposition}

The first hypothesis regarding the origin of sporadic Na layers suggested that it was the result of the ablation of a single large meteor (Clemesha et al., 1978). Later Clemesha et al. (1988) suggested that an initially thick layer, caused by meteor deposition, could be converted into a thin layer by wind shear. The same meteor deposition could be responsible for metallic ions which are redistributed in the same manner as the neutral sodium, explaining the observed correlation with sporadic E layers. Chemical loss processes, such as chemical oxidation, are responsible for the lack of observations below $90 \mathrm{~km}$. The rapid decay time is mainly explained as a result of advection. Only two groups seem to have investigated the possibility of a correlation with meteor showers (Hansen and von Zahn, 1990; Batista et al., 1989), but no conclusive evidence has been found for a correlation between sporadic Na layers and meteor showers.

Meteor count rates are characterized by both a strong diurnal and annual variation. The largest count rates are observed in summer and the lowest count rates are detected in winter. The mean daily peak rates in June and February differ approximately by a factor of 2 (Singer et al., 2004; Singer et al., 2005). There also seems to be a similar seasonal dependence in the number of sporadic Na layers observed per measurement hour found by Hansen (1989) and Heinrich et al. (2008). Taking into account the hours of measurement, Hansen (1989) found the occurrence rate of sporadic Na layers to be about a factor of 10 higher in June-August compared to November-February. Although this variation could be due to other fundamental differences between the summer and winter mesosphere, we examine the meteor count rates on 5 November 2005 to see if there is an unexpected increase of sporadic meteors as meteor showers not occur around this date. The radar backscatter from potential larger meteors is ruled out by the meteor signal analysis. However, assuming there is a correlation between micro meteors and larger meteors, it could reveal if there is an increased probability for a large meteor entering the atmosphere near Andøya. 


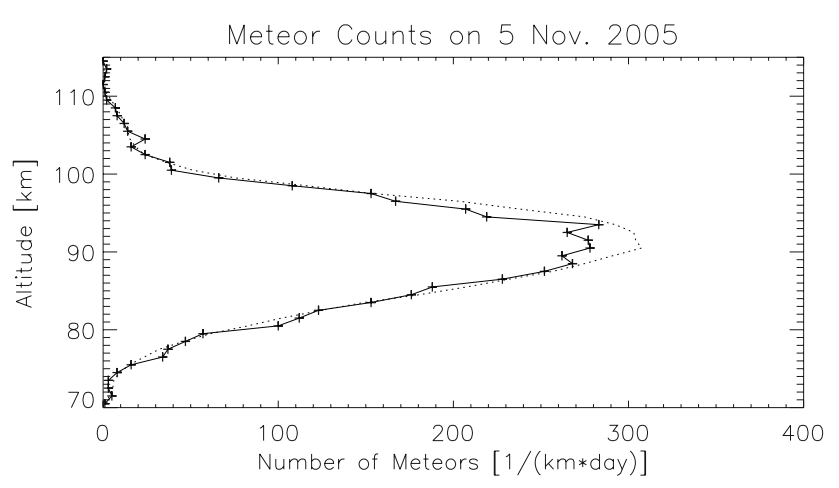

Fig. 3. The daily height profile of the meteor counts on 5 November 2005 measured over Andøya by the SKiYMET meteor radar. The dotted line shows the monthly average for November 2005.

Figure 3 shows the height profile of the meteor counts at Andøya for 5 November 2005. Compared to the monthly average, we do not find larger count rates than usual prior to the observed sporadic Na layer. In fact, the maximum meteor counts are a little less than the average. The width is about the same as the monthly mean profile, and so is the height of the peak. As seen in Fig. 4 we also find a relatively smoothly varying diurnal variation prior to the observation of the sporadic Na layer. Even though we cannot rule out the possibility that a single, large meteor has entered the atmosphere, we do not find an increased probability for this happening on 5 November 2005.

\subsection{Connection to sporadic E-layers}

A more accepted theory is based on correlations found between sporadic $\mathrm{Na}$ layers and sporadic E-layers below $110 \mathrm{~km}$ (e.g. von Zahn and Hansen, 1988). A sporadic Elayer is a thin layer of metallic ions, typically only $1-3 \mathrm{~km}$ wide occurring between 90 and $140 \mathrm{~km}$ (Mathews, 1998). Cox and Plane (1998) have suggested that the $\mathrm{Na}$ layer is produced by the conversion of $\mathrm{Na}$ ions in the sporadic $\mathrm{E}$ layer to neutral $\mathrm{Na}$. The first step in the neutralization process requires formation of molecular ions or ion clusters. The process of ion cluster formation is extremely sensitive to collision frequency and density, and therefore altitude. Weakly bound ion clusters are generally broken down to $\mathrm{Na}^{+}$ by atomic oxygen above $100 \mathrm{~km}$. At lower altitudes more strongly bound ion clusters are formed that are not influenced by atomic oxygen. The strongly bound ion clusters will eventually undergo dissociative electron recombination and produce Na. Thus, if a sporadic E-layer forms and then descends, the release of $\mathrm{Na}$ can happen very rapidly (Plane, 2003).

At low and mid-latitudes the formation of sporadic Elayers is explained with horizontal wind shears. However, the high inclination of the magnetic field lines at auroral latitudes makes this mechanism much less effective here. Ny-

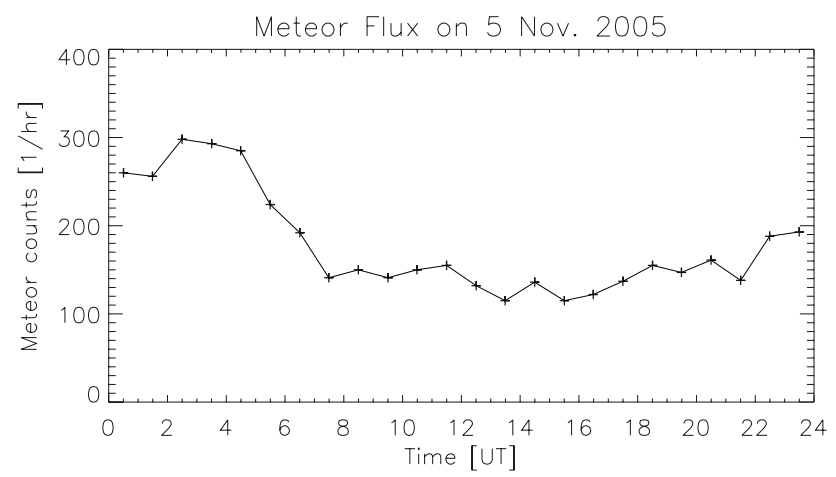

Fig. 4. Diurnal variation of meteor counts on 5 November 2005 measured over Andøya by the SKiYMET meteor radar.

gren et al. (1984) suggested that such layers can be formed solely by the influence of an electric field. In the presence of an electric field, ions in the E-region of the ionosphere drift partly in a direction perpendicular to both the electric and magnetic field directions and partly in the direction of the electric field. The strength of these forces depends on the ion-neutral collision frequency. The ion drift is also affected by neutral winds. The vertical ion motion, $v_{i z}$, which can lead to the accumulation of ions into a sporadic E-layer, can be described by:

$$
\begin{aligned}
v_{i z}= & \frac{\Omega_{i} v_{i}}{\Omega_{i}^{2}+v_{i}^{2}}\left[\frac{E_{N}}{B_{0}}+W_{E}\right] \cos I+\frac{\Omega_{i}^{2}}{\Omega_{i}^{2}+v_{i}^{2}} \\
& {\left[\frac{E_{E}}{B_{0}}-W_{N} \sin I\right] \cos I+\left[1-\frac{\left(\cos ^{2} I\right) \Omega_{i}^{2}}{\Omega_{i}^{2}+v_{i}^{2}}\right] W_{z},(2) }
\end{aligned}
$$

where $\Omega_{i}$ and $\nu_{i}$ are the ion gyro and collision frequencies, $B_{0}$ is the Earth's magnetic field strength, $I$ is the magnetic inclination angle, $E_{N}$ and $E_{E}$ the northward and eastward components of the electric field (assumed perpendicular to B), and $W_{N}, W_{E}$ and $W_{z}$ are the horizontal (northward and eastward) and vertical (positive upward) components of the neutral wind (Kirkwood and von Zahn, 1991). Simulations by Kirkwood and von Zahn (1991) show that ion layers are formed below $108 \mathrm{~km}$ by electric fields pointing purely westward or which have a southward component, and they can drift down to altitudes as low as $92 \mathrm{~km}$ within $30 \mathrm{~min}$. Observations by the Andenes magnetometer indicate a westward electrojet flowing just south of the station. This implies a south/west pointing electric field prior to our observation of the sporadic Na layer. The zonal wind measurements displayed in Fig. 5 show a wind reversal at about $97 \mathrm{~km}$. The zonal wind is westward above this height and eastward below. With the northward component of the geomagnetic field, this wind will cause positive ions to converge in this altitude region. Both the magnetometer observation and the zonal wind measurements make the conditions favourable for a formation of a sporadic E-layer below $100 \mathrm{~km}$. 

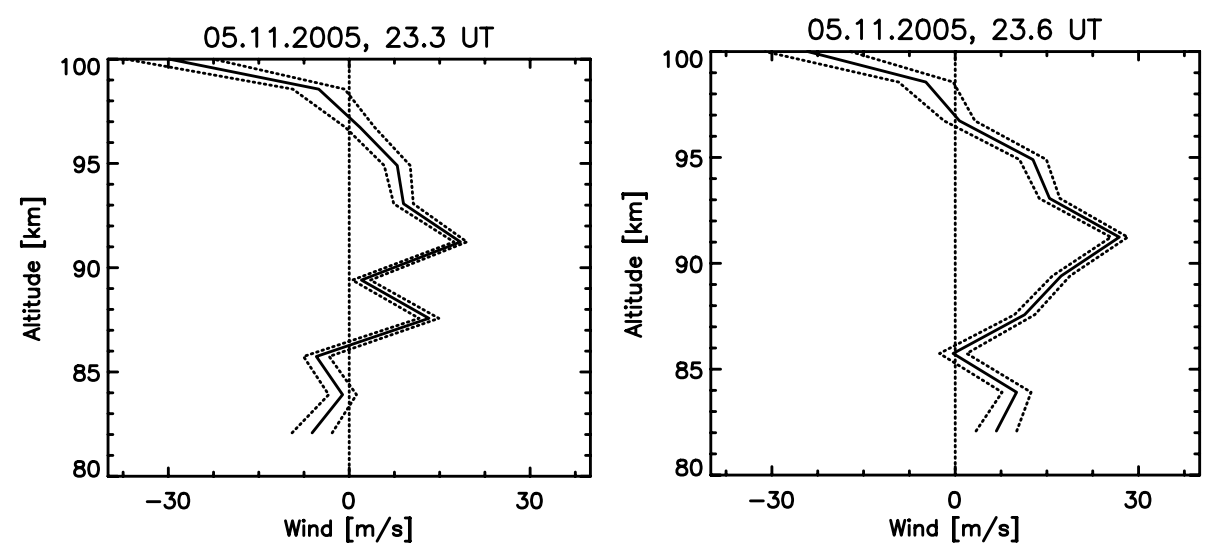

Fig. 5. 15 min averaged zonal winds measurement on 5 November 2005 observed by ALOMAR Weber Na lidar in beam 1 (pointed $20^{\circ} \mathrm{W}$ of zenith) (positive values correspond to eastward winds).

Ionograms from the EISCAT Troms $\varnothing$ Dynasonde were recorded every $5 \mathrm{~min}$ and a selection for the period 22:5023:30 UT is shown in Fig. 6. At 22:50, about $25 \mathrm{~min}$ prior to our observation of the sporadic $\mathrm{Na}$ layer, we see echoes from a sporadic E-layer. This time delay between the sporadic E-layer and the sporadic $\mathrm{Na}$ layer is consistent with conversion of $\mathrm{Na}$ ions to neutral $\mathrm{Na}$, similar to previous observations (Heinselman et al., 1998; Williams et al., 2006). However, the sporadic E-layer is not that evident 10 min later. At the time we observe the sporadic Na layer in beam 1, the echo power is weakened or fully absorbed. The observations coinciding with the time we observe the sporadic Na layer in beam 2, reveal a sporadic E-layer that seems to have descended to virtual heights of $80-85 \mathrm{~km}$, giving support for a correlation between sporadic $\mathrm{Na}$ layers and sporadic Es.

\subsection{Connection to a temperature dependent mechanism}

Observation of temperature and $\mathrm{Na}$ abundance at different latitudes, seasons and local times indicate that temperature has an effect on the $\mathrm{Na}$ abundance near the mesopause. Higher temperatures seem to facilitate the net production of sodium atoms due to a temperature dependent $\mathrm{Na}$ chemistry. The clustering processes are especially sensitive to temperature. For example, the reaction between $\mathrm{Na}$ and molecular oxygen has a Na loss rate proportional to $\mathrm{T}^{-1.3}$ (Plane and Rajasekhar, 1989). An increase in temperature will hinder the loss of $\mathrm{Na}$, which will result in an increase in the $\mathrm{Na}$ abundance. This knowledge led Zhou et al. (1993) to propose a temperature dependent mechanism for the formation of sporadic Na layers. They state that a temperature increase of $10 \mathrm{~K}$ in the mesopause region could double the $\mathrm{Na}$ concentration. Local temperature variations of this order of magnitude could easily be induced by atmospheric gravity waves, or other wave processes in conjunction with a background tidal wind system. More specifically, Zhou and Matthews (1995) suggested that the sporadic Na layers could be a re- sult of turbulent heating caused by wave breaking. Turbulence tends to deposit heat in a narrow altitude range.

Figure 7 shows temperature contour plots for our time interval of interest. There seems to be a wavelike temperature variation with maximum temperature occurring around 23:30 UT at $90-92 \mathrm{~km}$. In particular, we also find a local temperature enhancement within this maximum at the same time and height as the observed sporadic Na layer in beam 1 as shown in Fig. 8. The nocturnal measurements above Arecibo presented by Zhou et al. (1993), suggest a time lag of less than $1 \mathrm{~h}$ between the temperature and $\mathrm{Na}$ density. The temperature enhancement in beam 1 preceding the $\mathrm{Na}$ density increase is approximately $20 \mathrm{~K}$, which according to Zhou et al. (1993) could intensify the Na density by a factor of 4 , accounting for our observed $\mathrm{Na}$ density increase of approximately 3-4 times that of the background layer. On the other hand Fig. 8 also shows that we have intervals of large temperature variations, which do not seem to influence the $\mathrm{Na}$ density. In addition, the temperature increase occurs over a much wider altitude range than the sporadic Na layer, which indicates that a temperature enhancement cannot alone explain the small vertical extent of the sporadic Na layer. Further, we do not find the expected time lag between the negative temperature and density gradients. Assuming a shorter time constant the temperature increase cannot be the only mechanism responsible for the $\mathrm{Na}$ density increase.

The net wave field convergence zone could account for the production of a sporadic E field through the wind shear mechanism as mentioned above. Hooke (1969) calculated that a westward propagating wave would cause a local temperature maximum in the increased ion density layer. However, an eastward propagating wave would cause a temperature minimum in the ion layer. In winter there is a predominance of westward propagating waves due to the stratospheric wind system filtering out waves with eastward propagating phase. Considering that the sporadic $\mathrm{Na}$ layer observation rate is higher in summer than in winter (Hansen, 1989) 

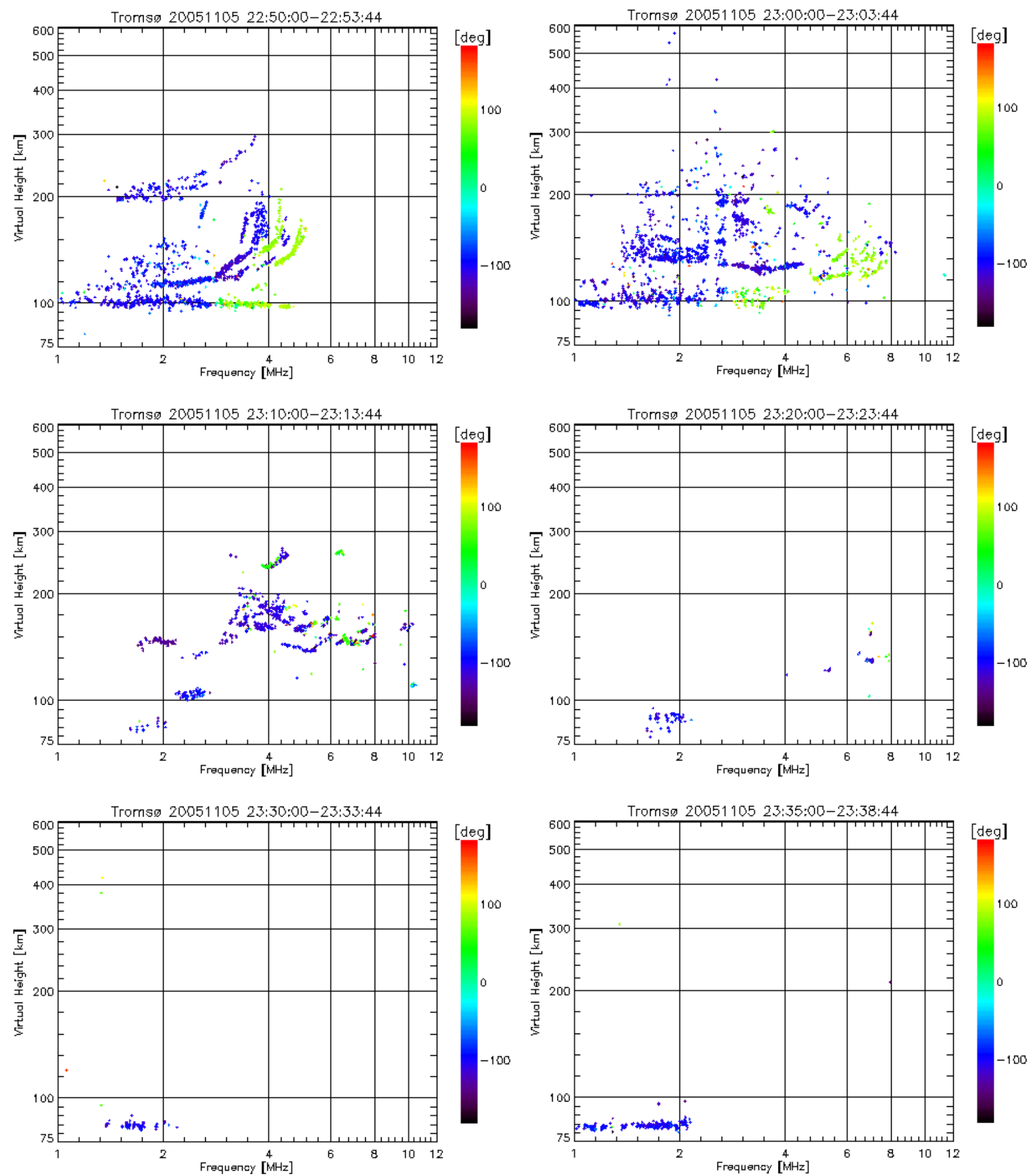

Fig. 6. Ionograms from the EISCAT Troms $\varnothing$ Dynasonde for selected time periods on 5 November 2005 . The colour scale shows the chirality of the echoes, $+90^{\circ}$ is for $\mathrm{X}$-mode and $-90^{\circ}$ for O-mode echoes. 

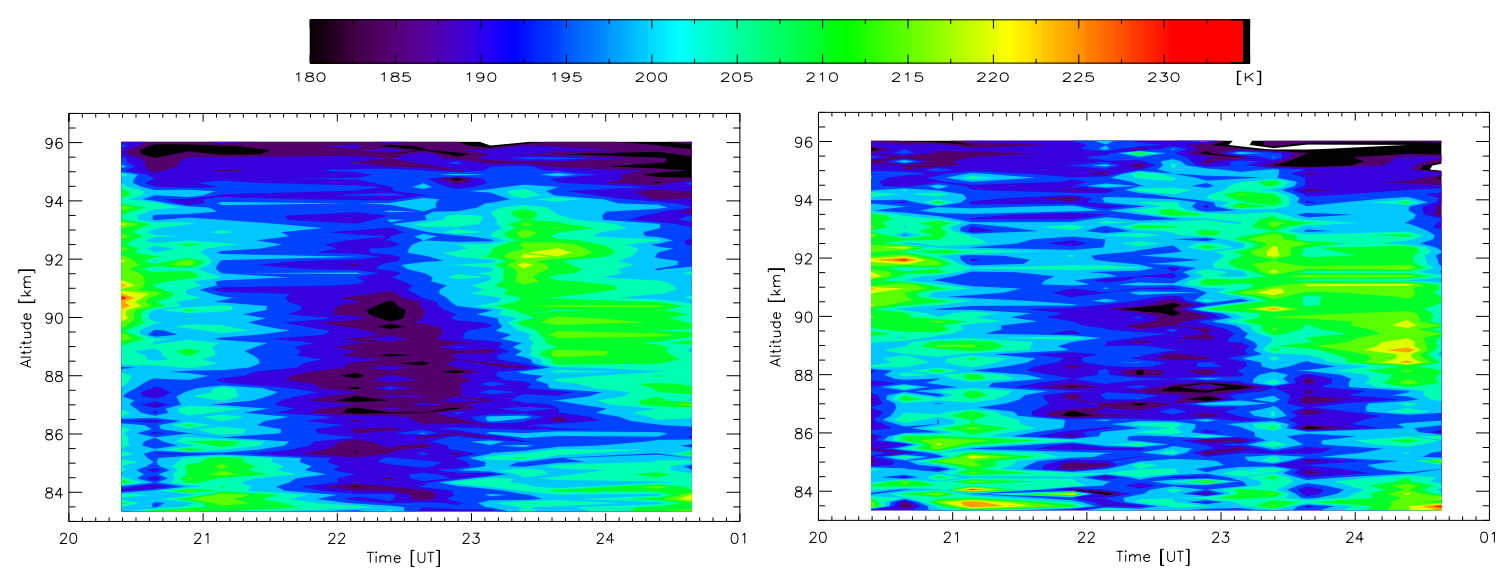

Fig. 7. Contour plots of $15 \mathrm{~min}$ averaged temperatures from the ALOMAR Weber Na lidar on 5-6 November 2005. Beam 1 (left) is pointing $20^{\circ} \mathrm{W}$ of zenith. Beam 2 (right) is pointing $20^{\circ} \mathrm{E}$ of zenith.
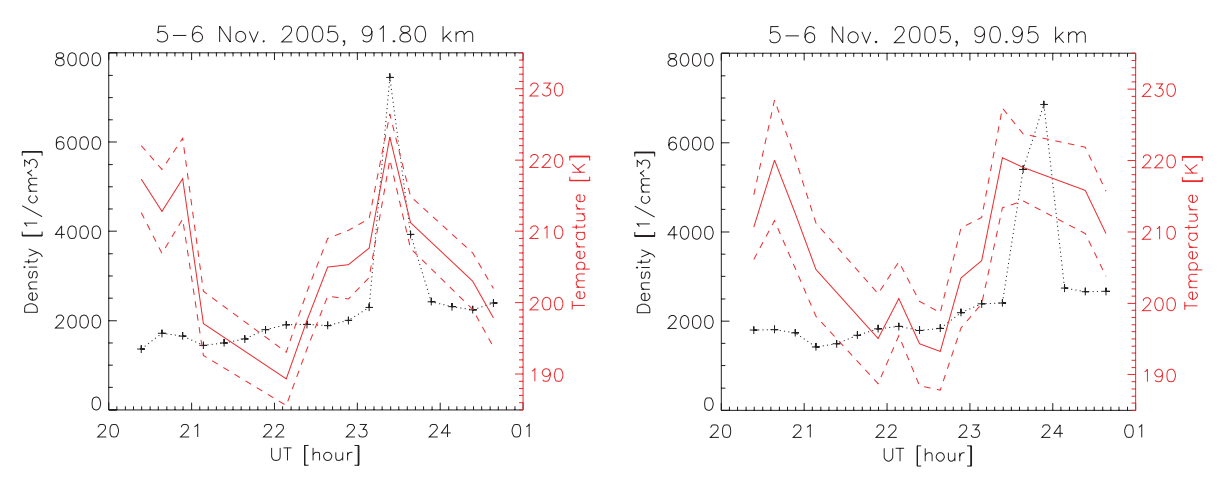

Fig. 8. 15 min averaged densities and temperatures from the ALOMAR Weber Na lidar on 5-6 November 2005 at the height of maximum density increase. Beam 1 (left) is pointing $20^{\circ} \mathrm{W}$ of zenith. Beam 2 (right) is pointing $20^{\circ} \mathrm{E}$ of zenith.

this might lead us to the conclusion that the temperature enhancement we observe is a by product of the waves dragging the sporadic E layer down to the Na layer, and not the actual source of the sporadic $\mathrm{Na}$ layer. In fact, Hansen and von Zahn (1990) found that most of the sporadic Na layers were close to a local minimum of the vertical temperature profile. However, when a temperature enhancement occurs in the same volume as the sporadic E layer it might slow down the $\mathrm{Na}$ loss processes, and in this manner be one of the mechanisms responsible for our observation of the sporadic $\mathrm{Na}$ layer.

\subsection{Connection to electron precipitation}

von Zahn et al. (1987) proposed that the sporadic Na layers which they observed at Andøya could be caused by auroral electron precipitation acting on meteoric smoke particles. Particles formed in situ by re-condensation of silicates, which became temporarily vaporized by the meteor ablation process, are called smoke particles (Hunten et al., 1980). Smoke particles embedded in the Na layer are not only a source for $\mathrm{Na}$, but might also act as a sink. During their slow sedimentation through the Na layer they might collect
$\mathrm{Na}$ atoms, molecules and ions on their surface. If such smoke particles are concentrated into a narrow layer by appropriate dynamical conditions, e.g. a vertical shear in the horizontal winds assuming that the particles are charged, auroral particles might be responsible for the observed sporadic Na layer. von Zahn et al. (1987) suggested that this mechanism could explain the correlation between sporadic $\mathrm{Na}$ layers and low sporadic E-layers, because impact of energetic electrons on smoke particles would also be responsible for the release of metallic ions.

Some selected observations made by the ALOMAR/UiO All-sky camera representative for the interval 22:3023:30 UT are displayed in Fig. 9. The period from about 22:30-23:05 UT is characterized by weak diffuse auroral emission. At 23:07 UT a strong intensification appears lasting for approximately $20 \mathrm{~min}$. The strongest emission fluxes are located just west of Andøya overlapping with the field of view of beam 1 of the Na lidar. The intensity ratio between $557.7 \mathrm{~nm}$ and $630.0 \mathrm{~nm}$ is largest in the beginning of the auroral intensification period as displayed in Fig. 10. Since the All-sky imager is not calibrated, we cannot estimate the 


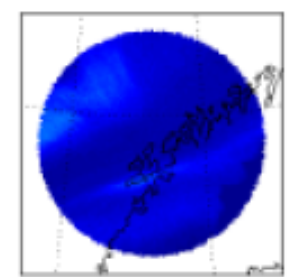

05 Nov 2005 23:07:50

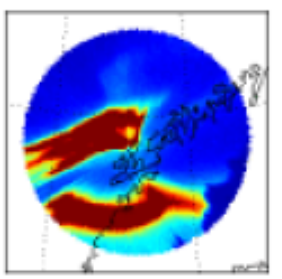

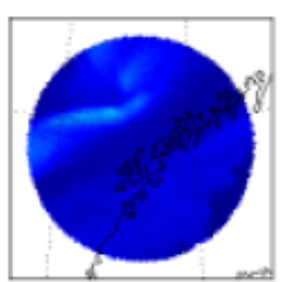

05 Nov 2005 23:11:51

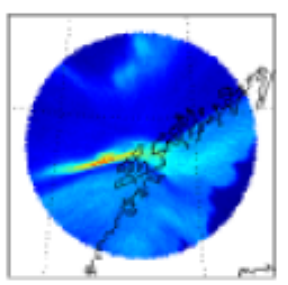

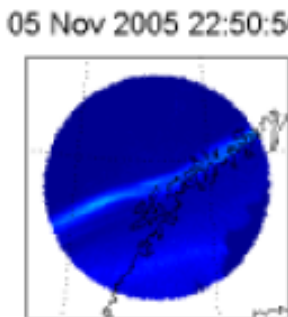

05 Nov 2005 23:24:50

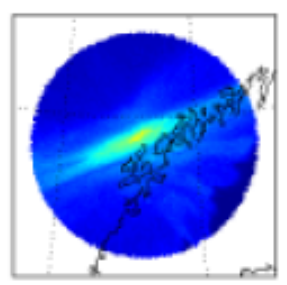

05 Nov 2005 23:01:50
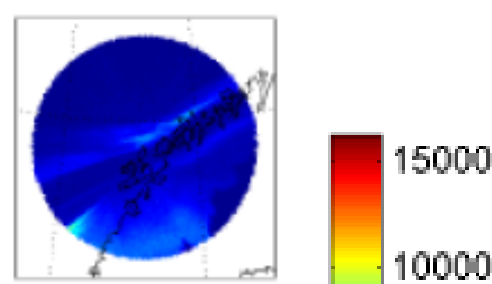

05 Nov 2005 23:30:50

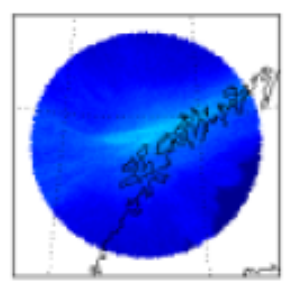

5000

Fig. 9. Observations from the ALOMAR/UiO All-sky Imager in the $557.7 \mathrm{~nm}$ band on 5 November 2005. The intensity is in arbitrary units.

characteristic energy of the precipitating electrons responsible for the observed emissions. However, the intensity ratio indicates a relative hard energy spectrum coinciding with the strong auroral intensification. To summarize, we observe an increased particle precipitation near and in the field of view of beam 1 in the same period we observe the strong increase in the $\mathrm{Na}$ density.

However, the particle precipitation alone is not enough to explain why the $\mathrm{Na}$ density increase is seen in just a narrow layer. We also need to have the right dynamical conditions to concentrate the smoke particles into a narrow layer. From some observations made with the Arecibo incoherent scatter radar, Mathews (1987) suggested that at times there exist rather thin layers of super-heavy negative ions in the $90-100 \mathrm{~km}$ region. He suggested that they were negatively charged smoke particles. By assuming that wind shear in the geomagnetic field generates the ion layers, we might use the zonal wind measurements from the $\mathrm{Na}$ lidar to see if we have favourable conditions for such layering to take place during our event. The zonal wind measurements show small gradients in the height region $89-95 \mathrm{~km}$ prior to the density increase. At about 23:20 UT, when the sporadic Na layer is seen in beam 1 , we find strong wind gradients above and below $91 \mathrm{~km}$ as shown in Fig. 5. The zonal wind is positive (toward east) in this height region. The cross product of eastward wind across the northward component of the magnetic field will drive negative ions downward. Where the zonal wind decreases, negative ions are driven more slowly downward, which might result in negatively charged smoke particles converging below $91 \mathrm{~km}$ at the same time we observe the sporadic $\mathrm{Na}$ layer in beam 1 .

To summarise, at the time of our observation of the sporadic Na layer on 5 November 2005, it seems as if the criteria for the auroral bombardment theory could be fulfilled. On

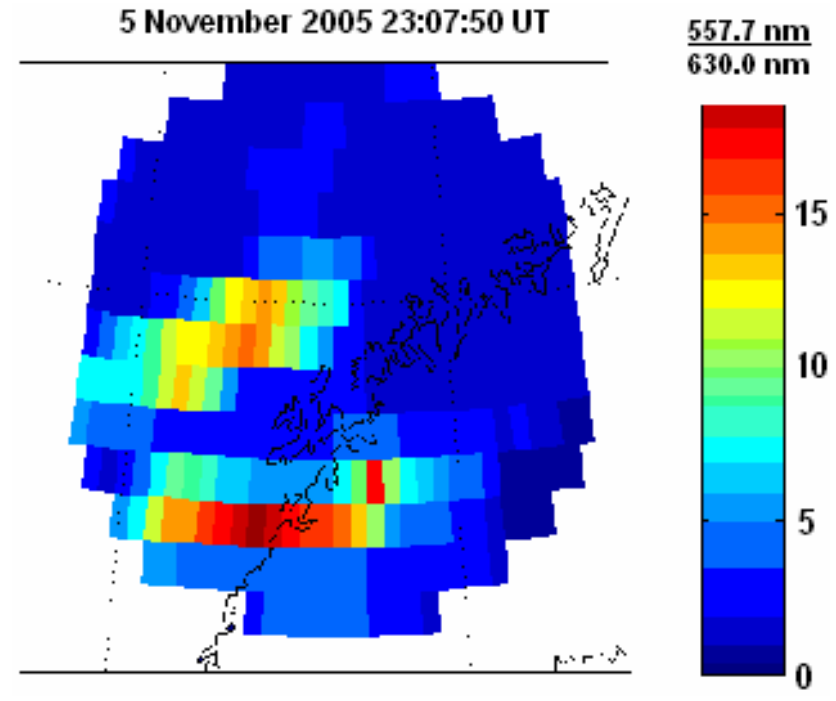

Fig. 10. The intensity ratio of the $557.7 \mathrm{~nm}$ and $630.0 \mathrm{~nm}$ as seen by the ALOMAR/UiO All-sky Camera on 23:07 UT on 5 November 2005.

the other hand, we do not know if such smoke particles exist here, or if they actually are concentrated into a thin layer. The zonal wind measurements indicate that if a possible layering phenomenon is due to the wind shear mechanism, it might be located too low compared to the observation of the sporadic Na layer. However, this could be compensated by an upward vertical wind. We could also speculate that the $\mathrm{Na}$ layer was produced elsewhere, as discussed in Sect. 3, where the zonal wind gradient was located at a slightly higher altitude. Either way, considering our observations we cannot disregard the auroral bombardment theory as one of the candidates to explain the formation of the high latitude sporadic $\mathrm{Na}$ layer we observe. 
The suggestion by von Zahn et al. (1987) has a weakness since it cannot account for sporadic Na layers observed at mid and low latitudes. Hansen and von Zahn (1990) addressed this weakness and therefore dismissed the assumption that energetic particle precipitation is commonly involved in the creation of sporadic Na layers. They do not, however, dismiss the possibility that such a process can occur in the auroral oval under special conditions. Although several publications (e.g., Heinselman et al., 1998) report the absence of auroral precipitation during a sporadic $\mathrm{Na}$ layer event, or even a decrease in the $\mathrm{Na}$ density during auroral precipitation, the observations by $\mathrm{Gu}$ et al. (1995) have given new support to the suggestion by von Zahn et al. (1987).

\section{Conclusion}

Even though sporadic Na layers have been observed and studied for almost 30 years, no theory seems adequate to explain all the accumulated observations. In this article, we have revisited some of the older theories regarding sporadic Na layer formation mechanisms, in addition to the more generally accepted causal relationship to sporadic E-layers when investigating a sporadic Na layer observed by the ALOMAR Weber Na lidar on 5 November 2005. Making use of the varied instrumentation on and near Andøya we find that more than one candidate is eligible to explain our observation of the sporadic Na layers. The sporadic Na layer coincides with both a sporadic E-layer, particle precipitation, and a temperature enhancement, making the ion-conversion theory, the auroral bombardment theory and a temperature dependent chemistry all potential formation mechanisms for the sporadic Na layer. We do not find an unexpected increase of meteors prior to the observation of the sporadic Na layer.

Based on the previous studies, such as Hansen and von Zahn (1990), the ion conversion theory seems to be the most likely candidate. On the other hand, taking into account that many event studies seem to focus on only one of the proposed theories, we emphasize the need for a simultaneous evaluation of the different theories in case there is more than one mechanism at work.

Acknowledgements. The ALOMAR Weber Na lidar is a cooperative effort of Colorado State University, NorthWest Research Associates/Colorado Research Associates Division (NWRA/CoRA), the Norwegian Defence Research Establishment (FFI), the LeibnizInstitute of Atmospheric Physics, and Andøya Rocket Range. This research was supported by The Research Council of Norway projects 165573 and 170855, AFSOR under contracts F4962003-C-0045 and FA9550-06-C-0129, and by the NSF under grants ATM-0545262 and ATM-0436703.

Topical Editor M. Pinnock thanks three referees for their help in evaluating this paper.

\section{References}

Arnold, K. S. and She, C.-Y.: Metal fluorescence lidar (light detection and ranging) and the middle atmosphere, Contemporary Phys., 44, 35-49, 2003.

Batista, P. P., Clemesha, B. R., and Simonich, D. M.: Horizontal structures in sporadic sodium layers at $23^{\circ} \mathrm{S}$, Geophys. Res. Lett, 18, 1027-1030, 1991.

Batista, P. P., Clemesha, B. R., Batista, I. S., and Simonich, D. M.: Characteristics of the sporadic sodium layers at $23^{\circ} \mathrm{S}, \mathrm{J}$. Geophys. Res., 94, 15 349-15 358, 1989.

Clemesha, B. R., Kirchhoff, V. W. J. H., Simonich, D. M., and Takahashi, H.: Evidence of an extraterristrial source for the mesospheric sodium layer, Geophys. Res. Lett., 5, 873-876, 1978.

Clemesha, B. R., Batista, P. P., and Simonich, D. M.: Concerning the origin of enhanced sodium layers, Geophys. Res. Lett., 16, 1267-1270, 1988.

Clemesha, B. R.: Sporadic neutral metal layers in the mesosphere and lower thermosphere, J. Atmos. Terr. Phys, 57, 725-736, 1995.

Collins, R. L., Hallinan, T. J., Smith, R. W., and Hernandez, G.: Lidar observations of large high-altitude sporadic Na layer during active aurora, Geophys. Res. Lett., 23, 3655-3658, 1996.

Cox, R. M. and Plane, J. M. C.: An ion-molecule mechanism for the formation of neutral sporadic Na layers, J. Geophys. Res., 103, 6349-6359, 1998.

Fricke, K. H. and von Zahn, U.: Mesopause temperatures derived from probing the hyperfine structure of the $\mathrm{D}_{2}$ resonance line of sodium by lidar, J. Atmos. Terr. Phys., 47, 499-512, 1985.

Gardner, C. S., Tao, X., and Papen, G. C.: Observations of strong wind shears and temperature enhancements during several sporadic Na layer events above Haleakala, Geophys. Res. Lett., 22, 2809-2812, 1995.

Gu, Y. Y., Qian, J., Papen G. C., Swenson, G. R., and Espy, P. J.: Concurrent observations of auroral activity and a large sporadic sodium layer event during ANLC-93, Geophys. Res. Lett., 22, 2805-2808, 1995.

Hansen G. and von Zahn, U.: Sudden sodium layers in polar latitudes, J. Atmos. Terr. Phys., 52, 585-608, 1990.

Hansen, G.: Plötzliche Natriumschichten in polaren Breiten in Höhenbereich 90-110 km, Ph.D. thesis, Physikalisches Institut, Universität Bonn, 1989.

Heinrich, D., Blum, U., Williams, B., Vance, J., She, C.-Y., Singer, W., and Hoppe, U.-P: Observations of wintertime mesopause temperatures with the ALOMAR Weber Na lidar during winter 2004/05, ESA SP-590, 133-137, 2005.

Heinrich, D., Nesse, H., Blum, U., Accot, P., Williams, B., and Hoppe, U.-P.: Summer sudden Na number density enhancements measured with the ALOMAR Weber Na lidar, Ann. Geophys., 26, 1057-1069, 2008.

Heinselman, C. J., Thayer, J. P., and Watkins, B. J.: A high-latitude observation of sporadic E-layer formation, Geophys. Res. Lett., 25, 3059-3062, 1998.

Hocking, W. K. and Thayaparan, T.: Simultaneous and collocated observations of winds and tides by MF and meteor radars over London, Canada $\left(43^{\circ} \mathrm{N}, 81^{\circ} \mathrm{W}\right)$, during 1994-1996, Radio Sci., 32(2), 833-865, 1997.

Hooke, W. H.: Electron, ion and neutral-gas temperatures in temperate latitude sporadic-E layers, Planet. Space Sci., 17, 737748, 1969. 
Hunten, D. M., Turco, R. P., and Toon, O. B.: Smoke and dust particles of meteoric origin in the mesosphere and stratosphere, J. Atmos. Sci., 37, 1342-1357, 1980.

Kirkwood, S. and von Zahn, U.: On the role of auroral electric fields in the formation of low altitude sporadic-E and sudden sodium layers, J. Atmos. Terr. Phys, 53, 389-407, 1991.

Mathews, J. D.: Sporadic E: current views and recent progress, J. Atmos. Sol.-Terr. Phys., 60, 413-435, 1998.

Mathews, J. D.: Some aspect of metallic ion chemistry and dynamics in the mesosphere and thermosphere, MAP Handbook, 25, 228-254, 1987.

Nygren, T., Jalonen, L., Oskman, J., and Turunen, T.: The role of electric field and neutral wind direction in the formation of sporadic E layers, J. Atmos. Terr. Phys., 46, 373-381, 1984.

Pitteway, M. L. V. and Wright, J. W.: Toward an optimum receiving array and pulse-set for the dynasonde, Radio Sci., 27, 481-490, 1992.

Plane, J. M. C.: Atmospheric chemistry of meteoric metals, Chem. Rev., 103, 4963-4984, 2003.

Plane, J. M. C. and Rajasekhar, B.: Kinetic study of the reactions $\mathrm{Na}+\mathrm{O}_{2}+\mathrm{N}_{2}$ and $\mathrm{Na}+\mathrm{N}_{2}$ over an extended temperature range, J. Phys. Chem., 93, 3135-3140, 1989.

Rees, M. H. and Luckey, D.: Auroral electron energy derived from ratio of spectroscopic emissions 1. Model computations, J. Geophys. Res., 79, 5181-5186, 1974.

She, C. Y., Vance, J. D., Williams, B. P., Krueger, D. A., Moosmüller, H., Gibson-Wilde, D., and Fritts, D. C.: Lidar studies of atmospheric dynamics near polar mesopause, EOS Trans. AGU, 83, 289-293, 2002.

Singer, W., von Zahn, U., and Weiss, J.: Diurnal and annual variations of meteor rates at the arctic circle, Atmos. Chem. Phys., 4, 1355-1363, 2004,

http://www.atmos-chem-phys.net/4/1355/2004/.
Singer, W., von Zahn, U., Batista, P. P., Fuller, B., and Latteck, R.: Diurnal and annual variations of meteor rates at latitudes between $69^{\circ} \mathrm{N}$ and $35^{\circ} \mathrm{S}$, ESA SP-590, 151-156, 2005.

Vance, J. D., She, C.-Y., and Moosmüller, H.: Continuouswave, all-solid-state, single-frequency $400-\mathrm{mW}$ source at $589 \mathrm{~nm}$ based on doubly resonant sum-frequency mixing in a monolithic lithium niobate resonator, Appl. Opt., 37, 4891-4896, 1998.

von Zahn, U., von der Gathen, P., and Hansen G.: Forced release of sodium from upper atmospheric dust particles, Geophys. Res. Lett., 14, 76-79, 1987.

von Zahn, U. and Hansen, T. L.: Sudden neutral sodium layers: a strong link to sporadic E-layers, J. Atmos. Terr. Phys., 50, 93104, 1988.

Williams, B. P., Fritts, D. C., Wang, L., She, C. Y., Vance, J. D., Schmidlin, F. J., Goldberg, R. A., Müllemann, A., and Lübken, F.-J.: Gravity waves in the arctic mesosphere during the MaCWAVE/MIDAS summer rocket program, Geophys. Res. Lett., 31, L24S05, doi:10.1029/2004GL020049, 2004.

Williams, B. P., Croskey, C. L., She, C. Y., Mitchell, J. D., and Goldberg, R. A.: Sporadic sodium and sporadic-E layers observed during the summer 2002 MaCWAVE/MIDAS rocket campaign, Ann. Geophys., 24, 1257-1266, 2006, http://www.ann-geophys.net/24/1257/2006/.

Zhou, Q., Mathews, J. D., and Tepley, C. A.: A proposed temperature dependent mechanism for the formation of sporadic sodium layers, J. Atmos. Terr. Phys., 55, 513-521, 1993.

Zhou, Q. and Mathews, J. D.: Generation of sporadic sodium layers via turbulent heating of the atmosphere?, J. Atmos. Terr. Phys., 57, 1309-1319, 1995. 